\title{
Ao Sul das referências: Reflexões decoloniais para desierarquizar os processos de produção de conhecimento
}

\section{South of the references: Decolonial reflections to desierarchize the processes of knowledge production}

Vera Martins $^{1}$
Rosane Rosa

Resumo: O artigo apresenta uma reflexão a respeito de uma experiência de pesquisa na área da comunicação e dos estudos feministas e de gênero, realizada com mulheres do Brasil e de Moçambique, que privilegiou a utilização de referenciais teóricos decoloniais. O texto discute aspectos relacionados às escolhas de autoras(es) e apresenta os conceitos: axé (SODRÉ, 2017) e disponer de una misma (TZUL TZUL, 2016), para evidenciar a potencialidade dos referenciais decoloniais para democratizar o processo de produção do conhecimento. Nesse contexto, afirmamos que os estudos que promovem o diálogo entre países do sul global, a partir da incorporação de referentes teóricos decoloniais, contribuem para reposicionar, socialmente, os sujeitos e nutrir o processo de teorização com as experiências de sua gente: autoras(es), pesquisadoras(es) de todos os níveis, comunidades, coletivos e movimentos sociais.

Palavras-chave: Produção do conhecimento; referências decoloniais; estudos feministas e de gênero.

Abstract: The article presents a reflection about a research experience in the area of communication and feminist and gender studies, carried out with women

1 Universidade Federal de Santa Maria (UFSM). Santa Maria, RS, Brasil. https://orcid.org/0000-0003-4412-6476. E-mail: martins.verissima@gmail.com

2 Universidade Federal de Santa Maria (UFSM). Santa Maria, RS, Brasil. https://orcid.org/0000-0003-0686-0944. E-mail: rosanerosar@gmail.com 
from Brazil and Mozambique, which privileged the use of decolonial theoretical references. The text discusses aspects related to the choices of authors and presents the concepts: axé (SODRÉ, 2017) and disponer de una misma (TZUL TZUL, 2016), to evidence the potentiality of decolonial references to democratize the process of knowledge production. In this context, we affirm that studies that promote dialogue between countries of the global south, based on the incorporation of decolonial theoretical references, contribute to the social repositioning of subjects and to nourish the theorizing process with the experiences of their people: authors, researchers from all levels, communities, collectives and social movements.

Keywords: Knowledge production; decolonial references; feminist and gender studies. 
"Invocando estas leis imploro-te Exu plantares na minha boca o teu axé verbal restituindo-me a língua que era minha e me roubaram" (NASCIMENTO, 1981)

\section{Invocações}

Este trecho do poema "Padê para Exu Libertador", do intelectual negro brasileiro Abdias Nascimento, nos situa em relação às estratégias de comunicação que emergem das premissas ancestrais africanas e que persistem em território brasileiro sustentando a ação política de resistências das comunidades afro-diaspóricas. Exu é o senhor das possibilidades, pois rege a comunicação entre todas as formas de vida, numa articulação complexa entre tecnologias, recursos humanos e naturais, sem que nenhuma ordem hierárquica dite sua ação. A desnaturalização das hierarquias está na base política do pensamento decolonial, introduz uma desordem na linearidade ocidental e, com isso, dá visibilidade a outros sentidos de mundo (OYĚWÙMí, 2017).

Os sentidos desse poema são a inspiração para este texto, que busca apresentar reflexões sobre o uso de referências teóricas decoloniais na realização de pesquisas científicas. Suas ponderações estão centradas na articulação entre o campo da comunicação e o dos estudos feministas e de gênero e se apoiam em uma experiência de pesquisa que transitou entre Brasil e Moçambique 3 . Trata-se de uma escrita atravessada por memórias de uma experiência de pesquisa intercultural, a qual se insere no cenário das discussões comunicacionais e se volta aos usos das redes sociais feitos pelas mulheres na internet. Essa utilização foi estudada nos

3 A pesquisa foi desenvolvida no âmbito do doutorado-sanduíche realizado em 2017-2018 na Universidade Pedagógica, em Maputo, no âmbito do Programa de Desenvolvimento Acadêmico Abdias Nascimento - Edital 02/2014 - SECADI/MEC/CAPES. 
dois países, através da análise de relatos feitos por mulheres na fanpage "Vamos juntas?", do Facebook (Brasil), e no grupo presencial Algo Mais (Moçambique).

Esta pesquisa, seus processos e resultados, se orientou ética e politicamente ao sul. E, quando pensamos e grafamos este termo - o sul - levamos em consideração, pelo menos, duas dimensões de significados: uma é geográfica e diz respeito ao mapa físico, morada localizável das instituições que abrigaram o estudo, das pesquisadoras que o desenvolveram e das pessoas da comunidade que interagiram como sujeitos participantes da investigação; a outra dimensão é política, onde o sul é espaço de memória, é berço epistêmico, é resistência social, é lugar de mirada, é lugar de sentir, é perspectiva de existência que atravessa as vidas e os textos sobre os quais vamos refletir. Nesse sentido, durante toda a investigação estivemos atentas às nossas práticas, para evitar - e esperamos ter conseguido - a reprodução de um essencialismo geográfico. Por isso, no âmbito das teorizações, convidamos a caminhar conosco no processo de investigação aquelas ideias que são frutos de decisões políticas de problematizar a hegemonia dos que sempre têm um "norte".

De todo o processo que envolveu a investigação - que durou 3 anos e 9 meses -, escolhemos apresentar neste texto dois momentos. O primeiro, que visa problematizar e discutir sobre quem está autorizado a produzir conhecimento, e de qual lugar social se dará, por meio de uma reflexão crítica a respeito da escolha das(os) autoras(res) para o referencial teórico. O segundo momento é a apresentação de dois conceitos, forjados no contexto intelectual decolonial e empregados na pesquisa: axé (SODRÉ, 2017) e dispor de si (TZUL TZUL, 2016). Ao apresentá-los, queremos evidenciar a potencialidade dos referenciais decoloniais como recurso para desierarquizar e democratizar o processo de produção teórica do conhecimento.

\section{Mirada metodológica}

As reflexões que serão abordadas neste texto foram articuladas para pensar a realidade das mulheres brasileiras e moçambicanas a partir de uma 
abordagem feminista. O campo teórico do feminismo foi profundamente modificado pela mirada decolonial de muitas intelectuais, como, por exemplo, Maria Lugones (2014), Gladys Tzul Tzul (2016) e Carla Akotirene (2019). Elas introduzem, além da problematização de gênero, outros elementos a partir dos quais é possível refletir sobre uma ideia de feminilidade, de nascer fêmea e vir a ser designada mulher em contextos situados. Elas reivindicam que elementos de classe, culturais, raciais e religiosos sejam considerados sem hierarquizações entre si, aplicados a cada contexto e articulados aos desejos e projetos dessas mulheres. Longe de significar um questionamento sobre o quão fundamental é a teoria feminista, este processo de questionamento complexificou e aprofundou os debates, assim como revelou a face hegemônica e os aspectos conservadores desta teoria, gestando uma abordagem mais justa e equitativa:

Quando não vemos o debate e a discussão como formas antagonistas e belicosas de comunicação, podemos praticá-los como meios retóricos para esclarecer as diferenças práticas e teóricas e para respeitar diferentes vozes e perspectivas feministas como algo que fortalece e não enfraquece as distintas lutas (FIORENZA, 2009, p. 43).

Nesse contexto de reflexão, neste artigo, nossa mirada metodológica se dará a partir da hermenêutica crítica feminista (FIORENZA, 2009). Nos inspiramos na hermenêutica da suspeita para tratar da questão da escolha das(os) autoras(es) e na hermenêutica da imaginação criativa, para refletir a respeito dos conceitos já mencionados.

Na hermenêutica da suspeita, recomenda-nos a autora, não devemos tomar os textos “ao pé da letra”, mas, antes, analisar que função eles desempenham no interesse da dominação. Esse exercício pode ser difícil emocionalmente, porque já interiorizamos a autoridade do texto acadêmico, e exige, então, que confrontemos nossas emoções, ansiedades e temores. Nas palavras de Fiorenza (2009, p. 198):

Uma hermenêutica da suspeita não deve ser confundida com uma hermenêutica da descoberta que assume que no mundo existe alguma 
ordem que pode ser descoberta se nos tornamos conscientes dos diversos disfarces utilizados para encobrir a Verdade e para disfarçar a realidade.

Assim, este giro hermenêutico nos possibilita uma vigilância sobre as estratégias dominantes de produção de sentido e torna visíveis os papéis e valores implicados em, por exemplo, pares dicotômicos e hierarquizados, como: masculino/feminino, superior/inferior, nós/eles. Já na hermenêutica da imaginação criativa, a autora recomenda procurar gerar visões utópicas ainda não realizadas, ou não realizadas plenamente. Nesse exercício, pode-se olhar para os textos para "sonhar" com um mundo de justiça e bem-estar e encontrar, na imaginação, o espaço de memória e possibilidades.

Graças a nossas capacidades imaginativas podemos nos colocar no lugar de outras pessoas, conectar-nos com seus sentimentos e participar de suas decisões e lutas. A imaginação histórica nos permite ver as lutas de mulh *res no passado e estabelecer conexões com nossas próprias lutas (FIORENZA, 2009, p. 202).

$\mathrm{Na}$ concepção da autora, esse giro se preocupa em trazer à tona a capacidade de conceber mudanças e perceber como as situações podem ser transformadas, assim como celebrar as pessoas que trouxeram a mudança (FIORENZA, 2009). As duas hermenêuticas orientam a construção reflexiva dos dois itens do texto a seguir.

"Olorum

Pai nosso e teu Exu de quem és fruto alado da comunicação e da mensagem" (NASCIMENTO, 1981)

\section{Quem pode ser chamada(0) de teórica(0)?}

A seleção das referências teóricas para o desenvolvimento da pesquisa é um dos procedimentos metodológicos que pedem de pesquisadoras e 
pesquisadores uma reflexão que envolve um alinhamento com os objetivos estabelecidos, mas que implica também - ainda que nem sempre conscientemente - uma tomada de posição política sobre a investigação. Na experiência de pesquisa Brasil-Moçambique sobre a qual estamos apoiando a elaboração deste texto, o processo de decidir quais referências iriam compor o corpo teórico passou por diversos momentos. No início dos estudos, partimos do campo da Comunicação e dos Estudos Feministas e de Gênero de forma bem abrangente, e depois consideramos a possibilidade de fazer um recorte exclusivamente feminista e com autoras mulheres. Finalmente, quando os estudos decoloniais passaram a compor nosso modo de problematizar e vislumbrar caminhos, fomos chamadas a complexificar (GANDARILLA, 2016) nossas escolhas.

Foi nesse momento que a hermenêutica da suspeita emergiu como um caminho para a construção desta complexidade, uma vez que nos convoca a questionar e desmistificar as estruturas de dominação inscritas nos textos, mas também nas nossas próprias experiências, inclusive aquelas como pesquisadoras (FIORENZA, 2009). Esse movimento de suspeita nos permitiu autorizar-nos a optar por autoras e autores da América do Sul, África e alguns poucos do norte global, desde que, em suas obras, houvesse um diálogo sensível com o sul, ou que suas reflexões apontassem críticas das relações hierárquicas implicadas nas relações norte-sul.

Queremos nos deter um pouco nessa afirmação sobre "autorizar-se", porque esse processo é fértil para uma reflexão sobre a adoção de referentes teóricos decoloniais. Fiorenza (2009, p. 198) alerta que "nós mulh"res não sabemos se textos gramaticalmente masculinos se dirigem a nós ou não. É por isso que precisamos pensar sempre duas vezes e perguntar se algo se refere a nós ou não". Este modo hegemônico de produção textual produz um efeito de nos colocar, como mulheres, fora do contexto de produção de conhecimento, gesto este que vamos internalizando por meio de inúmeros mecanismos sociais de opressão. Então, uma sensação de não pertencimento - muitas vezes, nem chega à consciência - nos impele a buscar percursos que nos legitimem 
e amparem neste lugar, e utilizar “autores consagrados” é um desses mecanismos.

Ao suspeitarmos dessa sensação de não pertencimento, e de seus desdobramentos sobre nosso fazer científico enquanto mulheres e, mais especificamente, mulheres do sul, temos a possibilidade de esboçar outros caminhos. Assim, o primeiro movimento, geralmente, é o de apresentar os "consagrados", para em seguida produzir uma extensa e exaustiva argumentação refutativa, com bases feministas e decoloniais, por exemplo. Uma leitura atenta da hermenêutica da suspeita (FIORENZA, 2009) nos mostra que isso é uma armadilha. A elaboração "confrontativa", que parece caminho obrigatório para nós, que queremos colocar no centro de nossas pesquisas pensamentos que habitam às margens sociais do pensamento acadêmico, na realidade evidencia que ainda estamos gravitando em torno de um "norte ideal" e empregando nossa energia criativa e intelectual de modo subordinado. Significa, ainda, que não partimos de nossa própria “cosmopercepção” (OYĚWÙMÍ, 2017), mas estamos nos reportando ao pensamento hegemônico, buscando um gesto de aceitação para que então nossas elaborações possam ser dignas de existir no universo teórico. Este tipo de compreensão é um dos objetivos do pensamento decolonial.

Trata-se, segundo José Gandarilla (2016), de restaurar a complexidade do mundo a partir de uma crítica ao pensamento moderno/colonial e seus sistemas de categorias universais, hierarquizadas e homogeneizadoras, para recusar o lugar de imobilidade dos sujeitos categorizados pelo projeto colonial. É este sistema que ampara a atribuição de papéis sociais generificados e retira as mulheres do âmbito da razão científica. Para o autor, o problema está nas categorias universais - como o subalterno - que encerram as pessoas em rotulações predeterminadas, escondendo suas práticas e saberes, silenciando suas vozes e não as reconhecendo como seus interlocutores.

$\mathrm{O}$ autor alerta que reconhecer as marcas do projeto colonial passa pela necessidade de compreender seu poder classificatório e de constante redução da complexidade do outro - que fica limitado a uma 
categoria estanque: mulher, índio, negro, de sua ética e suas práticas, devastando, assim, a diversidade humana. Desse modo, o desafio é migrar de categorias universais para categorias universalizáveis. Nesse sentido, deveria acontecer uma negociação - democrática e coletiva - com os grupos que representam a diversidade humana e isso nos daria condições sociais de propor categorias úteis de análise, que teriam potência de se tornar universalizáveis (GANDARILLA, 2016). Na visão do autor, categorias como equidade, reciprocidade e horizontalidade poderiam ser levadas à discussão, pois estão carregadas dessa potência de gerar respostas mais éticas e estéticas aos desafios da transformação social.

Nessa linha de raciocínio, duas autoras - bell hooks (2017) e Giovana Xavier (2019), intelectuais negras, estadunidense e brasileira, respectivamente - apontam como as críticas decolonais podem se traduzir em elementos para serem incorporados nas práticas de pesquisa. A primeira autora levanta, entre outros, dois aspectos. Ela afirma que o formato do texto deve ser objeto de reflexão, pois é uma opção política na medida em que promove mais ou menos acesso àquele conteúdo. Nessa perspectiva, hooks (2017) nos convoca a revisar o estilo de escrita, recusando o rebuscamento acadêmico que se reproduz em elaborações altamente abstratas, em jargão específico e em referências obscuras e difíceis de ler. Afirma, ainda, que é preciso se voltar para um estilo mais próximo do modo de falar popular, a fim de facilitar a ampla circulação do conhecimento, para que este seja um recurso acionado para a promoção de práticas transformadoras.

O outro aspecto relevante defendido pela autora é a construção de um "ponto de vista expansivo" de teorização (HOOKS, 2017). Essa afirmação emerge do questionamento sobre quem é e quem pode ser nominado como uma(um) teórica(o) e reivindica uma noção de autoridade compartilhada em todos os processos de produção de conhecimento (pesquisas científicas, contexto de ensino etc.). Partindo de exemplos do contexto feminista, a autora diz: "é que a produção de teoria feminista é um fenômeno complexo, que raras vezes é tão individual 
quanto parece ser e geralmente nasce de um envolvimento com fontes coletivas" (HOOKS, 2017, p. 87).

Nessa mesma direção, Giovana Xavier (2019) questiona o privilégio das teorizações acadêmicas em relação às narrativas orais como referências teóricas e como lugar de produção de conhecimento. A autora defende que é preciso olhar para outros espaços - fora dos muros universitários - para compreender a diversidade de conhecimentos que a sociedade está gestando. Esses outros espaços podem incluir as redes sociais, pois "em um país que trata a cultura acadêmica como um privilégio, o uso desta ferramenta de comunicação direta insere-se em um processo de escrita criativa que objetiva qualificar pontos de vista de mulheres negras como saberes" (XAVIER, 2019, p. 17). Assim, ela reivindica o reconhecimento de uma outra intelectualidade para

[...] evidenciar a aproximação entre quem somos e aquilo que produzimos. As respostas a esta forma inovadora de comunicar os conhecimentos científicos transitam desde a aceitação e reconhecimento à rejeição e à desautorização. Um despertar de afetos extremos que revela disputas de narrativas tanto na academia quanto no espaço público sobre conhecimento de quem está autorizado a produzi-lo (XAVIER, 2019, p. 17).

A partir de nossa experiência de pesquisa, privilegiando o uso de referências teóricas decoloniais para pensar os usos de redes sociais por mulheres brasileiras e moçambicanas, é possível afirmar que esta prática pode promover uma relação mais equivalente e justa entre produções teóricas, experiências e objetivos das(os) pesquisadoras(es) e pessoas que interagem como integrantes dos contextos onde ambientamos nossa investigação.

Este nosso reconhecimento encontra amparo nas reflexões de Alejandro Haber (2011), quando ele nos convida a buscar acessar o conhecimento em estado de mudança. Para o autor, esse tipo de conhecimento é uma conversação. Mas uma conversação em determinadas condições. Em primeiro lugar, acontece com sujeitos subalternos, ou com a face subalterna dos sujeitos; não é instrumental, ou seja, que se limita a recolher informações sobre como os sujeitos atribuem sentido 
à realidade, mas uma conversação com os outros sentidos da realidade; algo que nos interpele e que, cedo ou tarde, nos comova.

Em segundo lugar, é uma conversação com os movimentos sociais, comunidades ou coletivos, politicamente mobilizados para enfrentar o sistema hegemônico. Em terceiro lugar, é uma conversação ampliada, incluindo atrizes e atores considerados irrelevantes (Haber, 2011). Uma vez estabelecidos o desejo e as condições para a conversação, efetiva-se uma "situação de investigação", ou seja, uma conversação em que irão se articular muitas vozes. Na experiência de pesquisa sobre a qual estamos refletindo, isso significou articular as vozes teóricas, aquelas mulheres brasileiras e moçambicanas, e as vozes das pesquisadoras, e a pesquisa se constituiu em um espaço propício para o encontro e a copresença, permitindo que todas ouçam e falem em pertencimento, reconhecimento e solidariedade.

\section{Celebração dos saberes sentidos}

A imaginação criativa proposta por Fiorenza (2009) é acionada aqui como um recurso político para revistar os processos de produção do conhecimento, pois, ao mesmo tempo que a autora chama a atenção para a construção de cenários que permitam a transformação social, sua convocação à celebração daquelas pessoas e lutas já em curso nos afasta do imaginário que povoa a mente com ambientes solitários e estéreis dos laboratórios de ciência. O emprego da palavra celebração introduz sons e cores, instaura movimento e dinamismo nesse ambiente, lembrando que é possível conceber um processo de investigação onde os saberes da teorização e das experiências dos sujeitos não sejam desperdiçados em disputas de autoridade.

A partir dessa abordagem, a projeção da mudança passa pela visibilização de conceitos que resultam do debate decolonial. Para este texto escolhemos dois conceitos, entre muitas possibilidades do repertório já produzido por essa abordagem teórica, que emergem de contextos da comunicação e dos estudos feministas decoloniais. O primeiro é o axé - mobilizado pela alegria e pelo afeto -, conforme pensa o teórico da 
comunicação Muniz Sodré (2017). A reflexão do autor é resultado de um profundo conhecimento dos modos de vida social, cultural, econômico, religioso e político das comunidades afro- diaspóricas brasileiras, que ele nomeia como pensamento nagô. E o segundo conceito é o de disponer de una misma, pensado no âmbito feminista pela socióloga Gladys Tzul Tzul (2016), que o emprega a partir de um diálogo com a tradição feminista sobre o lugar político do desejo. As propostas desta autora e deste autor são tão críticas da matriz ocidental de pensamento, quanto propositivas de outra razão geográfica para um agir político que promova a transformação social em situações de opressão de cunho colonial, patriarcal ou capitalista.

A abordagem de Sodré (2019), no bojo do pensamento nagô, inicia por situar o processo de constituição da pessoa, que se dá em um contexto comunitário, dentro de posições interpretativas particulares, dos marcos de uma filosofia política e moral relativa às sociedades africanas.

Nesta linha de pensamento regida por uma cosmologia e ancestralidade, o ser humano constitui-se de materiais coletivos (procedentes de entidades genitoras divinas e dos ancestrais) e de uma combinação individual de materiais, responsáveis por sua singularidade (SODRÉ, 2017, p. 117).

Esse contexto institui outra temporalidade, onde data e fatos perdem a importância, pois se assenta na "narrativa de uma experiência existencial vinculada por famílias, vizinhos, conhecidos, toda a gente afim de uma comunidade" (SODRÉ, 2017, p. 115). Nessa cosmologia, o ser humano "partilha uma condição comum a animais, minerais e vegetais, assim como às divindades, investidas de idênticos elementos" (2017, p. 118).

E essa condição partilhada é estabelecida pelo axé. O autor nos explica que esse conceito visibiliza o modo como a cosmologia, organizada em filosofias, ao ser arrancada de sua origem se reorganiza e se reconfigura para sobreviver, resistir e persistir deste lado do Atlântico. Sodré (2017, p. 133, grifo do autor) define assim: "A palavra axé dá conta da força e ação, qualidade e estado do corpo e suas faculdades de realização. Axé 
é na verdade um potencial de realização ou de não realização, apoiado no corpo". Essa realização mobiliza a energia dos seres: divindades, homens e ancestrais, convocando as forças naturais dos reinos animal, vegetal e mineral. Assim, o axé é uma virtualidade, o sagrado como campo que transcende, que se atualiza ou se individualiza, que pede uma unicidade corporal, indissociando a palavra dos tons e dos gestos:

Experenciado como um conteúdo, acumulável e transmissível pela mediação corporal, o axé preside ao ciclo de trocas simbólicas, do dar e receber, fazendo funcionar códigos comunitários, presidindo às transformações e passagens de uma situação a outra (SODRÉ, 2017, p. 134).

Para a compreensão do axé, o autor aponta como decisivo o entendimento de dois aspectos: o afeto e a alegria, pois, na perspectiva nagô, a ordem dos fenômenos está ligada à primazia do sensível e das sensibilidades, e afastada dos processos racionalizados e intelectualizados.

No âmago de uma filosofia de diáspora, como o pensamento nagô, a alacridade entendida como "ponto de existência" é uma regência afetiva que propicia essa margem dentro de um contexto social marcado há séculos pela continuidade das políticas de servidão (SODRÉ, 2017, p. 24).

Nesse contexto, o afeto significa o exercício de uma ação sobre uma/ outra sensibilidade - não necessariamente sobre um ser vivo - que carrega conteúdos de emoção e de um estado particular de consciência; já a alegria é um modo fundamental da existência nagô, não como afeto circunstancial, mas como um regime concreto e estável de relacionamento com o real, como uma potência ativa da existência dos indivíduos (SODRÉ, 2017). A alegria não é um afeto circunstancial, mas um regime concreto e estável de relacionamento com o real e, portanto, uma potência ativa. "Por isso não existe propriamente o sujeito da alegria. Há, sim, o sujeito da emoção, objeto da sensação, até mesmo o sujeito de um sentimento, mas alegria é regência, algo que possibilita a existência dos sujeitos" (SODRÉ, 2017, p. 151), e se relaciona, consequentemente, com os saberes da vida prática. 
Assim, é este axé, em suas manifestações de afeto e alegria, que dá base para a resistência social empreendida pelas comunidades negras a partir de seus terreiros: "Mas, ao invés de um discurso lamentoso, de vitimização ou mesmo recalcamento, de tudo que aconteceu, a liturgia negra reconhece a realidade da mudança [...]" (SODRÉ, 2017, p. 152).

Na reflexão do autor, é essa lógica relacional que permeia as formas de organização comunitária dos descendentes africanos, dando lastro ao seu agir político, que "não costuma aparecer nas lentes etnológicas e se faz visível na mobilização de recurso para a consolidação de alianças internas ao grupo e nas táticas de aproximação com a sociedade global hegemônica" (SODRÉ, 2017, p. 172). Porém, mesmo invisível, essa mobilização existe apoiada em manifestações de axé e alegria.

O axé é uma energia que atravessa o agir político,

Ao mesmo tempo individual e coletivo, mas também ao mesmo tempo pré-individual e impessoal. Há o axé dos deuses, dos elementos naturais, dos indivíduos vivos e dos ancestrais, portanto, há um múltiplo de intensidades que se organizam no campo da comunicação de um comum. Este é atravessado por um sincretismo de afetos, além de práticas de elaboração e absorção [...] (SODRÉ, 2017, p. 134).

Assim, o axé se inscreve na dinâmica da continuidade da existência para conformar, não um discurso lamentoso e de vitimização de tudo que aconteceu, mas uma liturgia que reconhece a realidade da mudança.

Nessa mesma vertente crítica, encontramos uma densa teorização feminista que, impactada pela abordagem decolonial, se volta para as condições situadas das mulheres para visibilizar as marcas da transformação, frutos do combate das injustiças, das desigualdades e das opressões, abrindo assim o espectro de compreensão sobre as experiências femininas. Nesse contexto, destacamos as ponderações de Tzul Tzul (2016), que trazem uma reflexão sobre a noção de transformação social, em que a autora chama a atenção para o fato de que, geralmente, não se toma em conta que, ao mesmo tempo que algo se transforma, algo se conserva. Esse pensamento é uma crítica à ideia revolucionária 
de transformação, de que é preciso destruir e desfazer tudo o que existe e reconstruir a partir do nada. Nessa abordagem, por exemplo, muitas vezes, o uso das redes sociais digitais é questionado em sua legitimidade e efetividade enquanto luta social. É preciso lembrar que o uso das redes é uma das faces da trama histórica dos movimentos, que atualiza e expande possibilidades, bem como promove acesso e abre espaço para as vozes subalternas.

Para a autora, a transformação social advém do impulso da capacidade humana de produzir e reproduzir formas coletivas de viver no mundo, a partir de outra maneira que não seja a de dominação, de exploração e de privação: “[...] la transformación deja de estar centrada em la totalidade de relaciones de dominación, abriendo passo más bién para la possibilidad de/formar, re/formar lo existente a partir de esfuerzo colectivos situados y específicos" (TZUL TZUL, 2016, p. 172).

Ao pensar nas distintas circunstâncias dessa condição situada do feminino, a autora toca nos desafios do debate interseccional. Ela entende que o caminho é encontrar semelhanças nas formas de opressão, sem deixar de reconhecer e ressaltar o conjunto de variações particulares e específicas. Ou seja, trabalhar com a noção de que não pode haver um feminino abstrato, mas sim um feminino situado. Tzul Tzul (2016) enfatiza que é preciso reconhecer, ainda que nessa condição situada, que mulheres e homens podem escamotear e burlar a dominação, uma vez que podem ler suas regras e não só as enfrentar diretamente, mas também jogar com elas.

Para a autora, o que está em questão é a luta conjunta, desde a condição de mulheres, para poderem dispor de si mesmas. A partir disso, é fundamental reconhecer seu campo estratégico de lutas, onde se estabelece uma série de táticas para organizar a vida, com esforços no sentido de burlar o poder e a ordem simbólica. Além disso, há o intuito de escapar da certeza dos discursos e das práticas que insistem em constituir ou obrigar as mulheres ao ajuste da dicotomia vítima/heroína.

Trata-se de recusar a ideia de que as mulheres sempre foram oprimidas de uma forma "aplastante", para poder encontrar e visibilizar as 
formas variadas nas quais elas impulsionaram e fizeram valer suas capacidades, principalmente nos contornos comunitários de reprodução da vida (ou em redes). "[...] de ninguna manera considero que el acto político de resistir se encuentre sólo atravessado por sufrimiento y dolor. Más bien, las luchas de las mujeres y los hombres han de ser interpretadas a partir de la imaginación y creatividad [...]" (TZUL TZUL, 2016, p. 198).

Conforme frisa a autora, há uma força das mulheres que emana do mundo cotidiano (as relações) e que fica invisibilizada pelas análises de corte liberal, porque esse olhar desconsidera o mundo da reprodução da vida. Então, é preciso estudar os vínculos das mulheres com outras mulheres, "por que es principalmente de las relaciones entre mujeres desde donde se habilita el reconocimiento de los deseos y se consige la fuerza para desplegarlos" (TZUL TZUL, 2016, p. 176).

A autora resgata a noção do impulso e da potência do desejo feminino como forma de subversão dos limites impostos pelo caráter patriarcal nas diversas esferas da vida: "Pensar desde el deseo, más bien, pone en otro lugar las dificultades y permite analizar más allá de las formas convencionales como se prescribe la manera en que las mujeres han de liberarse (los derechos, la participación, la colectividad de la tierra)" (TZUL TUZL, 2016, p. 180). Os limites se efetivam como a impossibilidade de dispor de si e o desejo como impulsionador da libertação e da participação individual e coletiva. Nas palavras da autora,

[...] pensar desde el deseo alimenta, o por lo menos pone en otro lugar, las formas comunales a través de las cuales las mujeres nos producimos al interior de las tramas con otras mujeres y con otros hombres jóvenes, convocando a redefinir los términos de equilibrio (TZUL TZUL, 2016, p. 181).

Dessa forma, Tzul Tzul (2016) ressalta a necessidade de, para além de estudar os limites impostos e as impossibilidades, voltar os esforços de compreensão para as lutas contra os limites. O que não significa negar ou ignorar o conjunto de dificuldades e custos simbólicos e factuais das dificuldades, mas sim não se limitar nem se deixar imobilizar por ele. 
[...] disponer de una misma significa basicamente tener la posibilidad de desplegar el deseo en condiciones situadas. Las condiciones en las que existimos establecen límites y simultáneamente abren posibilidades, el deseo desplegado en tal sentido es algo así como una energía individual y colectiva capaz de erosionar y mover esos límites y ampliar por tanto las posibilidades de disposición de una misma (TZUL TZUL, 2016, p. 190).

A autora reitera que não se trata de omitir as circunstâncias nas quais estamos inseridas e que nos limitam a capacidade de dispormos de nós, mas reconhecer e afirmar que não somos a determinação mecânica das pessoas e estruturas com as quais nos relacionamos, somos capazes de negociar e agir estrategicamente em condições situadas. Nesse sentido, o desafio é gerir nossas trajetórias individuais e seguir produzindo luta coletiva para criar condições de possibilidade para vivermos em "tramas comunitário-comunais" - ou em redes - e ter nisso uma base concreta e afetiva para resolver nossos problemas.

"Ofereço-te Exu

O ebó das minhas palavras" (NASCIMENTO, 1981)

\section{Agrado em palavras}

Os conceitos de axé e disponer de una misma, no contexto da nossa pesquisa, foram fundamentais para pensar o desejo das mulheres de ampliar a compreensão sobre sua realidade. Eles acionaram olhares e reflexões que abriram espaço para nosso encontro com esses sujeitos silenciados pelo pensamento colonial em outro lugar. Este lugar não é mais só o da resignação - ou da rebeldia episódica como contam os livros da história oficial -, mas de pessoas que estiveram em constante processo de tensionamentos, enfretamentos e de empreendimentos para transformar sua condição. No caso das mulheres, o gesto de apreender práticas transculturais, que disputam os sentidos de toda uma narrativa, significa, novamente, reposicioná-las na categoria do humano. 
Esse modo de organização-movimentação elabora e sistematiza conhecimentos dentro de um "pensar-vivendo", sem intelectualizar, ou seja, sem fazer do pensamento uma esfera cognitiva separada da vida comum. "Não sendo essência, mas movimentação do pensamento, a ideia só existe na medida em que se comunica, isto é, que se vincula a outras ideias" (SODRÉ, 2017, p. 95, grifo do autor). No contexto da nossa pesquisa, o entendimento da comunicação como condição para existência foi importante na compreensão dos recursos disponibilizados pelas mídias sociais, para as lutas e a realização dos desejos das mulheres. Essas mídias têm possibilitado a comunicação porque promovem a circulação das ideias emergentes de vários grupos de mulheres, facilitando a vinculação delas com as práticas e as experiências, expandindo os espaços de acolhida e pertencimento das mulheres.

Os agrados e as obrigações para Exu, o orixá da comunicação, devem ser depositados nas encruzilhadas. Este lugar que, desde uma perspectiva ocidental da ordem e da linearidade desestabilizada pela possibilidade da dúvida, numa visão decolonial, se reveste de abertura e potência, de celebração do encontro. É a potência gestada por esta abertura que pode nos reconectar com a complexidade dos saberes das pessoas do sul global. Afirmamos que os estudos que promovam o diálogo entre países do sul global, a partir da incorporação de referentes teóricos decoloniais, são uma forma de reposicionar socialmente os sujeitos e democratizar a produção de conhecimento.

Nossa afirmação é possível porque o caminho de reflexão decolonial que percorremos nos convocou, o tempo todo, para atuarmos na desierarquização das relações que se estabelecem nos processos de pesquisa, ou seja, no universo de produção do conhecimento científico. O percurso que escolhemos como pesquisadoras integra nosso agir político, que se articula com todos os movimentos críticos às teorizações que não promovam capacitação e fortalecimento da resistência, que vêm sustentando a vida no sul colonizado. Nossas opções teóricas levaram em conta que este tipo de conhecimento deve dar suporte, por exemplo, ao ativismo libertador dos movimentos sociais e, ainda, ser sistematizado de tal modo 
que possa ser partilhado de forma escrita e oral, garantindo o acesso democrático ao processo de construção teórica e aos repertórios produzidos.

Esse objetivo de desierarquização que move o pensamento decolonial também significa um movimento libertador no interior dos processos de produção do conhecimento, porque não pretende disputar um lugar nos centros hegemônicos do pensamento, não almeja uma inversão de polos entre o norte e o sul. Ao se oferecer como caminho outro, como uma alternativa, libera todas e todos que se deixam afetar por ele do desperdício de recursos pessoais e coletivos, implicados em ocupar e se manter em espaços de dominação.

Livres da pressão, podemos nos voltar para o sul. Somos capazes de nos nutrir com as experiências de sua gente: autoras e autores, pesquisadoras(es) de todos os níveis, comunidades, coletivos e movimentos sociais. Em conversação, podemos produzir conhecimento, conseguimos nos comunicar - axé verbal - em continuidade com diversas matrizes culturais, conectadas(os) com as interferências das práticas humanas e suas narrativas, em que todas e todos o conhecem, produzem e narram desde seus lugares situados, sendo cada movimento celebrado. Axé!

\section{Referências}

FIORENZA, E. S. Caminhos da sabedoria: uma introdução à interpretação bíblica feminista. São Bernardo do Campo: Nhanduti Editora, 2009.

GANDARILLA, J. Epistemologias do sul: Intelectual crítico decolonial e universalidade transmoderna. Conferência de abertura (anotações pessoais). In: CONGRESSO INTERNACIONAL EPISTEMOLOGIAS DO SUL: PERSPECTIVAS CRÍTICAS, 1. 2016, Foz do Iguaçu, PR: UNILA, 2016.

HABER, A. Nometodología Payanesa: Notas de metodología indisciplinada (con comentarios de Henry Tantalean, Francisco Gil García y Dante Angelo). Revista Chilena de Antropología, n. 23, p. 9-49, 2011. Disponível em: https://bit.ly/2Ny7hpJ. Acesso em: 1 set. 2018.

HOOKS, B. Ensinando a transgredir. A educação como prática de liberdade. São Paulo: Editora WMF Martins Fontes, 2017.

O feminismo é para todo mundo: Políticas arrebatadoras. Rio de Janeiro: Rosa dos Tempos, 2019.

LUGONES, M. Colonialidad y Género: Hacia un Feminismo Descolonial. In: MIGNOLO, Walter et al. Género y decolonilidad. Ciudad Autónoma de Buenos Aires: Del Signo, 2014. 94 p. 
MARTINS, V. S. "Cria tua casa, cria teu futuro": experiências e práticas sociopolíticas na comunicação em redes das mulheres brasileiras e moçambicanas para dispor de si. 2019. 259 f. Tese (Doutorado em Comunicação) - Programa de Pós-Graduação em Comunicação, Universidade Federal de Santa Maria, Santa Maria, 2019.

NASCIMENTO, Abdias. Padê de Exu libertador. Disponível em: https://bit.ly/3jt66Gd. Acesso em: 1 set. 2019.

OYĚWÙMÍ, O. La invención de las mujeres. Una perspectiva africana sobre los discursos occidentales del género. Bogotá, Colombia: Editorial en la frontera, 2017.

SODRÉ, M. Pensar Nagô. Petrópolis, RJ: Vozes, 2017.

TZUL TZUL, G. Sistemas de Gobierno Comunal Indígena. Mujeres y tramas de parentesco em Chuimeq' ena'. Guatemala: Editorial Maya Wuj, 2016.

XAVIER, G. Você pode substituir mulheres negras como objeto de estudo por mulheres negras contando sua própria história. Rio de Janeiro: Malê, 2019.

\section{Sobre as autoras}

Vera Martins - Doutora em Comunicação Midiática pelo Programa de Pós-Graduação em Comunicação da Universidade Federal de Santa Maria - UFSM, com bolsa doutorado-sanduíche na Universidade Pedagógica de Moçambique, pelo Programa Abdias Nascimento/CAPES. Docente do Departamento de Ciências da Comunicação da mesma instituição - Campus Frederico Westphalen/RS. No presente artigo, a autora elaborou a discussão teórico-metodológica, realizou a coleta e interpretação dos dados e redigiu o texto.

Rosane Rosa - Doutora em Ciências da Comunicação e da Informação pelo Programa de Pós-Graduação em Comunicação e Informação da Universidade Federal do Rio Grande do Sul - UFRGS. Docente do Departamento de Ciências da Comunicação, do Programa de Pós-Graduação em Comunicação - POSCOM da Universidade Federal de Santa Maria - UFSM. Coordenadora do Programa Abdias Nascimento/CAPES entre a UFSM e a Universidade Pedagógica de Moçambique UP/MZ. Professora Colaboradora da UP/MZ. No presente artigo a autora orientou todo o processo de realização da pesquisa, participou da seleção dos dados em torno dos quais se desenvolveria a reflexão e fez revisão do texto.

Data de submissão: 31/08/2020

Data de aceite: $25 / 11 / 2020$ 